\section{Working memory}

in Down's

syndrome:

Training the

rehearsal strategy

\section{Annick Comblain}

\author{
Laboratoire de Psycholinguistique, \\ Universite de Liege, \\ Liege, Belgium.
}

Verbal short term memory skills of individuals with Down's syndrome are very poor (Hulme and MacKenzie, 1992; Bower and Hayes, 1994). This study reports on the verbal short term memory skills of individuals with Down's syndrome and on the possibility of increasing memory span durably by using a rehearsal training strategy. Three tasks (letter span, digit span and word span) were presented to two groups of 12 individuals with Down's syndrome as a pre-test. A global span measure was established for each individual. Each group contained four children, four teenagers and four young adults. The groups had similar memory span and mental age at the beginning of the study. None of these individuals seemed to clearly rehearse. One group of 12 was exposed to an intensive rehearsal training during eight weeks (half an hour a week). The methodology was inspired from that used by Hulme and MacKenzie (1992), and partially from that used by Broadley and MacDonald (1993). The other group of 12 received no training. After the training, the three initial memory tasks were presented again to the two groups as a post-test. The trained participants significantly improved their memory span, whereas the non-trained participants did not improve at all. Only the trained individuals showed, at this time, clear signs of systematic rehearsal. Two other post-tests were presented to them, one six weeks and the other six months after the first post-test. The trained participants did not seem, at these times, to rehearse systematically any more. Their memory performances fell significantly lower than after the first posttest but remained significantly higher than at the beginning of the study.

(C) 1993,1999. The Down Syndrome Educational Trust Down Syndrome Research and Practice 1994, 2 (3) 123-126
Participants

All the participants selected for the study were French speaking. The children and the adolescents attended special schools in the area of Liege (Belgium). The eight adults had previously attended special schools but at the time of the study attended a day centre for moderate mentally retarded adults. Two groups of 12 participants were selected. Each group contained half women and half men. The mean chronological age of the children was eight years (SD: 18 months), the mean mental age was 3.5 years (SD: 3 months), the mean memory span was 1.71 (SD: 0.27). The mean chronological age of the adolescents was 16.7 years (SD: 31 months), the mean mental age was 4.4 years (SD: 7 months), the mean memory span was 2.37 (SD: 0.33). The mean chronological age of the adults was 26.11 years (SD: 39 months), the mean mental age was 4.3 years (SD: 7 months), the mean memory span was 1.75 (SD: 0.68).

\section{Method}

A developmental age was calculated for each subject using the EDEI (Echelles Différentielles d'Efficience Intellectuelle, Perron-Borelli and Mises, 1974). A memory span level was also established for each of the 24 individuals. Three tasks were used:

a. Digit span: digit strings (from 2 to 8 digits) were presented to the participants. The participants were asked to repeat the digits immediately after the examiner (five sets of $2,3,4, \ldots \ldots .8)$. The digit span was the maximum string of digits an individual was able to repeat correctly (in presentation order) after the examiner.

b. Letter span: the method was identical to the one used for digit span. The letters were phonologically dissimilar.

c. Word span: the method was identical to the one used for digit span. The words used were monosyllabic and phonologically dissimilar.

As all these measures were extremely low, a global memory span was established for each subject by calculating the mean of these three measures. After this base line was established, one group of 12 participants received a rehearsal training during eight weeks (the experimental group) whereas the second group received no training (the control group). At the end of the training session, a memory post-test was given to the two groups. Six weeks after, a second posttest was given, and six months after the end of the training session, a third and last one completed. All the participants were seen individually, both in the testing and training sessions.

\section{Rehearsal training}

Materials: 70 colour pictures $(8.5 \mathrm{~cm} \times 6.5 \mathrm{~cm})$ representing five semantic categories (animals, fruits, vegetables, furniture and toys). Before the beginning of the training procedure, the examiner presented all the pictures to the participants in a naming task.

Procedure:the training procedure contained eight progressive steps.

Step 1 to Step 4: visual representation

Step 1: visual presentation of pictures from the same semantic category. The examiner presented a picture to the participant while he named it. The participant repeated the name 


\begin{tabular}{|l|l|c|c|c|c|c|}
\hline \multicolumn{2}{|l|}{ Experimental group } & $\begin{array}{c}\text { Memory span } \\
\text { Pre-test }\end{array}$ & $\begin{array}{c}\text { Memory span } \\
\text { Post-test 1 }\end{array}$ & $\begin{array}{c}\text { Memory span } \\
\text { Post-test 2 }\end{array}$ & $\begin{array}{c}\text { Memory span } \\
\text { Post-test 3 }\end{array}$ \\
\hline Children & Mean & 1.58 & 2.83 & 2.42 & 2.00 \\
\hline Adolescents & Mean & 2.25 & 3.33 & 2.67 & 2.67 \\
\hline Adults & Mean & 2.08 & 2.99 & 2.67 & 2.75 \\
\hline & Group Mean & 1.97 & 3.05 & 2.58 & 2.47 \\
\hline Control group & & & & 1.67 & 1.50 \\
\hline Children & Mean & 1.84 & 1.89 & 2.18 & 2.08 \\
\hline Adolescents & Mean & 2.50 & 1.42 & 1.42 & 1.42 & 1.35 \\
\hline Adults & Mean & Group Mean & 1.92 & 1.83 & 1.75 & 1.64 \\
\hline
\end{tabular}

Table 1. Memory span at pre-test, post-test 1, 2 and 3

of the picture. The examiner turned the picture face down on the table and the participant had to recall the name of the presented picture. If the participant succeeded in this task, the examiner presented the picture once again while naming it and added a second picture. The procedure went on in this way until the participant failed to recall the set of pictures.

i.e. Examiner: dog-Subject:- dog/E: dog, cat-S: dog, cat......

Step 2: visual presentation of pictures from different semantic categories. The procedure was the same as in the first step, but the pictures presented came from different semantic categories.

i.e. E: dog - S: dog / E: dog, apple - S: dog, apple......

Step 3: visual presentation of pictures from the same semantic category. The procedure was the same as that used in Step 1, but the examiner did not repeat all the items from the beginning and only the last picture presented was on the table.

i.e. E: dog - S: dog / E: cat - S: dog, cat.......

Step 4: visual presentation of pictures from different semantic categories. The procedure was the same as that used in Step 3, but the pictures presented came from different semantic categories.

i.e. E: dog - S: dog / E: dog - S: dog, apple......

Step 5 to Step 8: verbal presentation of the items.

The progression of the exercises was the same as that used in the presentation. In order to help the participants remember the number of items, the examiner raised one finger each time he said a word.

\section{Results}

Table 1 summarises the memory span of the experimental and the control group before the training session (pre-test), at the end of the training session (post-test 1), six weeks after the end of the training (post-test 2) and six months after the training (post-test 3).

There were no significant differences in memory performance between the experimental group and the control group at the beginning of the study ( $\mathrm{t}$ value $=.235$, NS).

\section{Experimental group/ Control group: global analysis}

Figure 1illustrates the level of memory performance in the experimental and control group of the pre-test and post-test 1,2 and 3.

A oneway ANOVA was used to determine whether there was any significant difference between the memory performance at the pre-test, and post-tests 1,2 and 3 . There was a significant effect of the time of the memory assessment $(F=7.60 ; d f=3,44 ; p<0.001)$ for the experimental group. Memory performance before the training session was significantly lower than performance at post-test 1 (just after the training session) $(p<0.05$, Student-Newman-Keuls test). There was a significant decrease in the performance between the post-test 1 and the post-tests 2 and $3(p<0.05$, Student-Newman-Keuls test) but the memory performance at the post-tests 2 and 3 remained significantly higher than performance at the pre-test $(p<0.05$, Student-NewmanKeuls test). There was no significant difference between memory performance at the post-test 2 or post-test 3 .

Another oneway ANOVA showed that there was no significant difference between the four memory tests in the control group $(F=.64 ; d f=3,44 ; N S)$.

\section{Experimental group/ Control group: global analysis} Figure 2 shows the changes in memory span performance in the three sub-groups of the experimental group (children, adolescents and adults). 


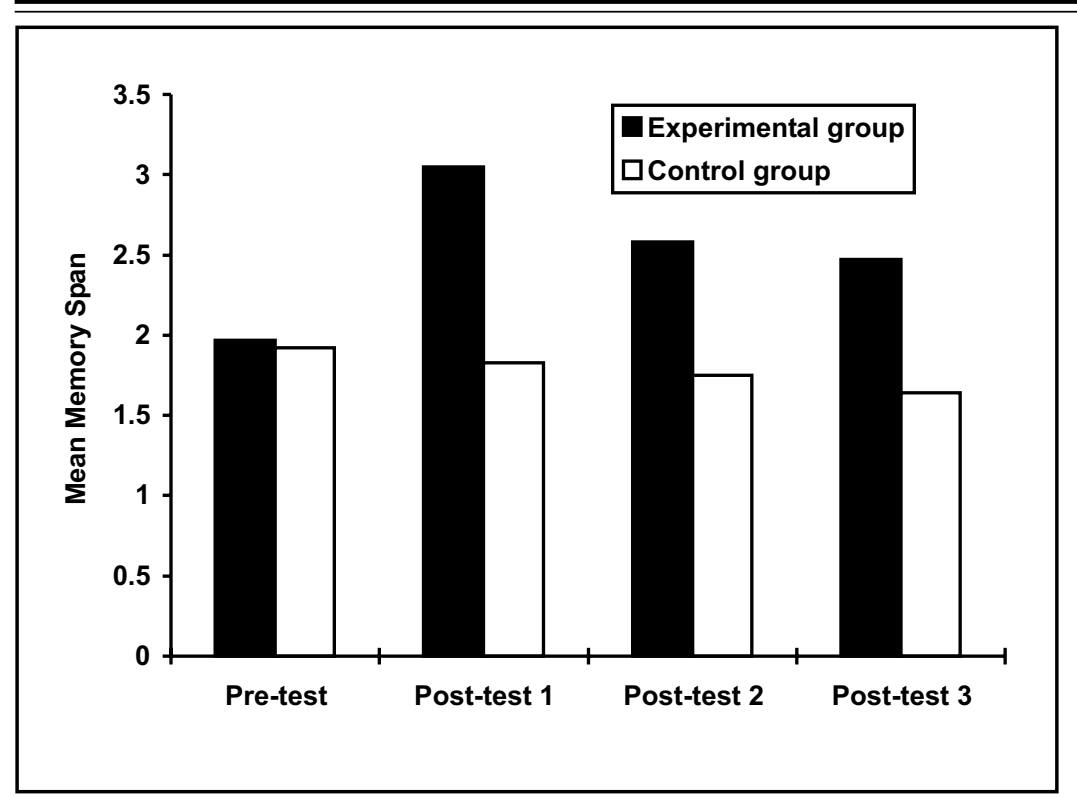

Figure 1 - Memory span level in the experimental and in the control groups.

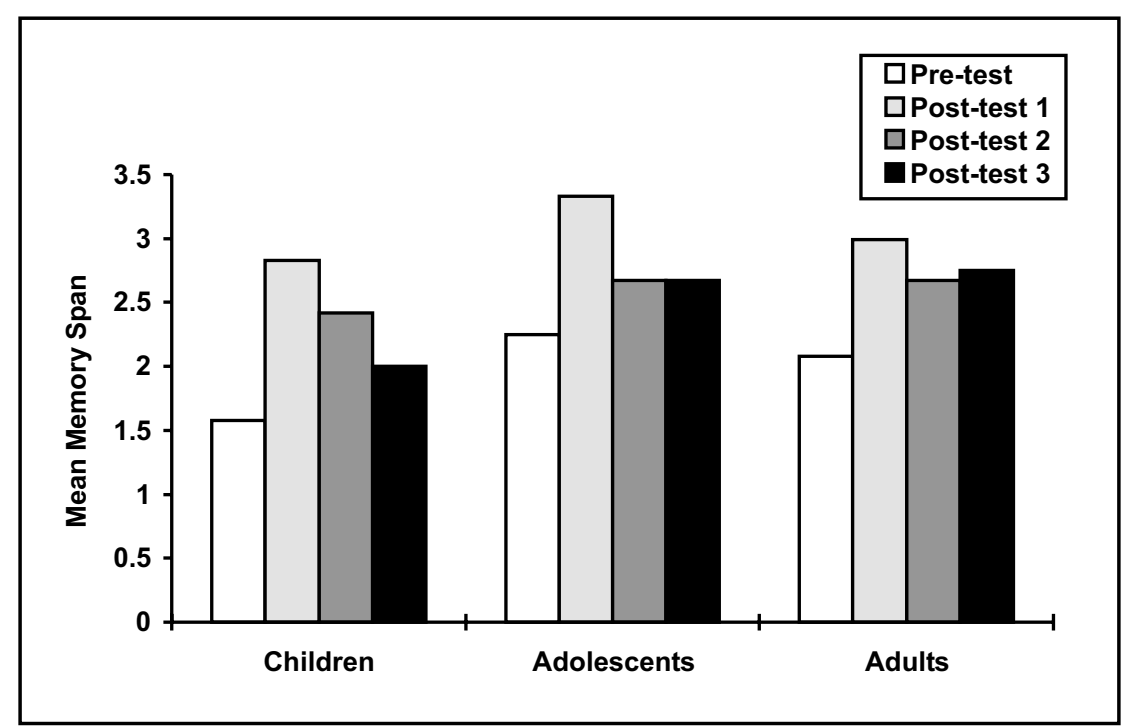

Figure 2. Changes in memory performance in the sub-groups of the experimental group.

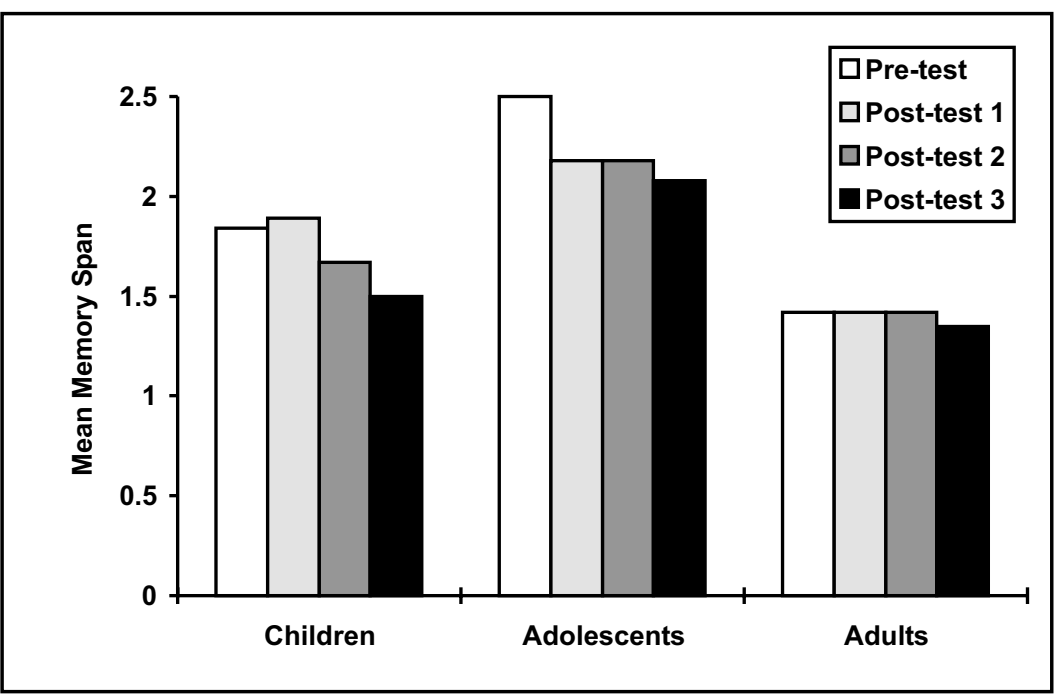

Figure 3. Changes in memory performance in the sub-groups of the control group.
It is difficult to interpret the results of the sub groups performance because of the small number of individuals in each of these sub groups. Another ANOVA analysis for the group of children determines a significant effect of the times of the memory assessment for children $(F=4.38 ; \mathrm{df}=3,12 ; \mathrm{p}<0.05)$ and for adolescents $(F=5.89 ; \quad d f=3,12$; $\mathrm{p}<0.01)$ but not for adults $(\mathrm{F}=1.22$; $\mathrm{df}=3,12 ; \mathrm{NS})$. Fisher's LSDTest showed that children's performance at pre-test were significantly lower than at posttest $1 \quad(p<0.05)$ and at post-test 2 $(p<0.05)$. Children also showed lower performances at post-test 3 than at post-test $1(p<0.05)$. Pre-test, post-test 2 and 3 were not significantly different. Memory performances of adolescents were significantly lower at the pre-test than at the post-test 1. Performances at post-tests 2 and 3 were significantly lower than performances at post-test 1 .

Figure 3 shows the changes in memory span performance in the three sub groups of the control group (children, adolescents and adults).

In these sub groups, there was an effect of the times of the assessment on the memory performance in the children $(F=2.23 ; d f=3,12 ; N S)$. Fisher's LSD Test showed that children perform lower at the post-test 3 than at pre-test and post-test 1 . Adolescents and adults had similar results at the four memory assessments (respectively $\mathrm{F}=.92$; $d f=3,12 ; N S ; F=.03 ; d f=3,12 ; N S$ ).

\section{Discussion}

It seems possible to significantly increase memory span in individuals with Down's syndrome by using a rehearsal training strategy. After eight weeks of training the totality of the trained individuals show clear signs of using rehearsal strategy whereas they did not show these signs before the training session. At post-test 1, four adolescents and two adults showed clear lip movements; four children and two adults used their fingers in order to facilitate the recall. Such behaviours seemed to disappear progressively at post-test 2 and are completely nonexistent at post-test 3.

The decrease of performance associated with the surrender of clear rehearsal behaviour suggests that participants stop using such strategies rather than consolidate or internalise them using a subvocal rehearsal strategy. 
Some recent data (Gathercole and Baddeley, 1993 and Gathercole, Adams and Hitch, 1994) suggests that normal four year old children do not engage in subvocal rehearsal during auditory memory span tasks. Henry (1991) and Heffernan, Hitch and Halliday (1993) support the same conclusion. The experiments they conducted with five year old children show that young children are not impaired by articulatory suppression as are older children and adults, suggesting then, that five year old children do not use a subvocal rehearsal strategy. The data available on typically developing children can help in interpreting the results of this experiment with individuals with Down's syndrome. The mean mental age of the children, adolescents and adults were respectively 3.5 years, 4.4 years and 4.3 years respectively. If we assume that five year old children do not engage in subvocal rehearsal during auditory memory span tasks, we can suppose that individuals with Down's syndrome with a mental age of under five do not use subvocal rehearsal either. If they do so as a result of intensive and specific training, they lose the strategy as soon as the training session stops. It would be interesting to know if typically developing young children can be trained to use a rehearsal strategy and whether they continue to use it long after the training session is stopped.

The important finding of this study is the demonstration that auditory short term memory performance can be improved in individuals with Down's syndrome. If, as Baddeley and Gathercole (1993) suggest, short term memory skills are strongly related to language acquisition, it is very important to improve these skills in children with Down's syndrome.

\section{References}

Baddeley,A. (1986) Working memory. Oxford: Oxford University Press.

Bower,A. and Hayes,A. (1994) Short term memory deficits and Down's syndrome: A comparative study. Down's Syndrome: Research and Practice, 2 (2), 47-50.

Broadley,I. and MacDonald,J. (1993) Teaching short term memory skills to children with Down's syndrome. Down's Syndrome: Research and Practice, 1 (2), 56-62.

Hulme,C. and MacKenzie,S. (1992) Working memory and severe learning difficulties. London: Erlbaum.

Gathercole,S.E. and Baddeley,A.D. (1993)Working memory and language. Hove: Erlbaum.

Henry,L.A. (1991) Development of auditory memory span: the role of rehearsal. British Journal of Developmental Psychology, 9, 493-411

Heffernan,T.M., Hitch,G.J. and Halliday,M.S. (1993)Dissociation of the word length effect and active rehearsal in young children. Manuscript submitted for publication.

Perron-Borrelli,M. and Misès,R. (1974) Epreuves Différentielles d'Efficience Intellectuelle. Issy-lesMoulineaux: Editions Scientifiques et Psychologiques.

Address for correspondence:

Annick Comblain,

Laboratoire de Psychologuistique,

Universite de Liege,

Liege, Belgium.

\section{Spanish Publications}

\section{Spanish Edition}

Coleman, M. and Rogers, P. (Eds): Medical Care in Down Syndrome: A Preventive Medicine and Early Management Approach.

This book is now available in a Spanish edition, entitledAtencion Medica en el Sindrome de Down. It is published by Fundacio Catalana Sindrome de Down, C/. Valencia, 231, 08007 Barcelona, Spain.

\author{
Spanish Book \\ Early intervention in children with Down's syn- \\ drome \\ A book on early intervention in children with Down's \\ syndrome has been published recently in Spanish \\ by ASSIDO. More information can be obtained \\ from Mr. Isidoro Candel, ASSIDO, Avda. Miguel de \\ Cervantes, s/n/ Apartado 2048, 30009 Murcia,
}

